\title{
Minimising food waste: a call for multidisciplinary research
}

\author{
M. Carmen Alamar ${ }^{1}$, Natalia Falagán ${ }^{1}$, Emel Aktas $^{2}$, Leon A. Terry ${ }^{1 *}$ \\ *Correspondence to L. A. Terry, Cranfield University, Bedfordshire, UK, MK43 0AL. Email: \\ 1.a.terry@cranfield.ac.uk
}

${ }^{1}$ Plant Science Laboratory, Cranfield University, Bedfordshire, UK, MK43 0AL

${ }^{2}$ School of Management, Cranfield University, Bedfordshire, UK, MK43 OAL

\begin{abstract}
Food losses and waste has always been a significant global problem for mankind, and one which has become increasingly recognised as such by policy makers, food producers, processors, retailers, and consumers. It is however an emotive subject whereby the extent, accuracy, and resolution of available data on postharvest loss and waste is questionable such that key performance indicators on waste can be misinformed. The nature and extent of food waste differs amongst developed economies, economies in transition, and developing economies. Whilst most emphasis has been put on increasing future crop production, far less resource has been and is still channelled towards enabling both established and innovative food preservation technologies to reduce food waste while maintaining safety and quality. Reducing food loss and waste is a more tractable problem than increasing production in the short to medium term, as its solution is not directly limited, for instance, by available land and water resources. Here we argue the need for a paradigm shift of current funding strategies and research programmes which will encourage the development, implementation, and translation of collective biological, engineering, and management solutions to better preserve and utilise food. Such cross disciplinary thinking across global supply chains is an essential element in
\end{abstract}


the pursuit of sustainable food and nutritional security. The implementation of allied technological and management solutions is reliant on there being sufficient skilled human capital and resource. There is currently a lack of robust postharvest research networks outside of the developed world, and insufficient global funding mechanisms which can support such interdisciplinary collaborations. There is thus a collective need for schemes which encourage inter-supply chain research, knowledge exchange and capacity building to reduce food losses and waste.

\section{Keywords}

Postharvest loss, sustainability, food security, fresh produce

\section{The balance between increasing food production and minimising waste}

The world's population is predicted to reach 9.6 billion people by $2050 .{ }^{1}$ To support this burgeoning population, projections are centred on increasing food production by at least $70 \%$.

2 The challenge of guaranteeing food security has never been greater. Food security is a dynamic concept that has changed over the recent decades. It was originally defined at the 1974 World Food Summit, with the focus on the volume and the stability of food supplies. However, over time the definition has evolved to capture a more complex and multidimensional concept comprising nutrition, safety, and socio-cultural aspects. ${ }^{3}$ In this context, the current four dimensions of food security are: availability, accessibility, utilisation, and stability of food provision. ${ }^{4,5}$

According to recent forecasts, increases in productivity will also need to be based on higher cropping intensities ${ }^{6}$ but there will be major challenges in reconciling increased irrigated crop production with water resources availability. The World Economic Forum 2015 identified the 'water crises' as one of the top five global risks to society due to the multifunctional impact of water on socio-economic development, health and sanitation, aquatic ecosystems and 
agricultural production. ${ }^{7}$ The global demand for water continues to rise steadily due to increases in world population and consequent changes in dietary habits, living standards, and to support socio-economic development. ${ }^{8}$ Climate change, with greater climate uncertainty and extremes, will exacerbate the impacts on water resources availability and crop productivity particularly in food insecure regions including South Asia and sub-Saharan Africa. ${ }^{9}$ Considering the limited and often exhausted resources we have access to, food waste should be avoided as far as possible, as it implies additional environmental impacts such as methane and carbon dioxide emissions that may aggravate climate change 10,11 and ecosystem deterioration. As such, food waste has become increasingly recognised as a global problem by policy makers, food producers, processors, retailers, and consumers. ${ }^{12}$ More sustainable food systems with both improved agricultural efficiency and supply chain management are required. 13

A supply chain can be defined as a network that integrates growers, processors, manufacturers, wholesalers, retailers (and consumers) coordinating the flow of products, information, and money between actors in production and consumption. ${ }^{13,14}$ According to Irani and Sharif, ${ }^{15}$ the main players or areas involved in the food supply chain are the economic sector (market pricing, demand management, financial metrics, and consumption trends), agriculture (improving cultural practices and management to increase sustainable production), postharvest technology (processing, storage, transportation, and quality control), and environment. Closer communication and collaboration among those multidisciplinary stakeholders would promote more sustainable supply chains which will lead to a reduction in the current food loss and waste.

\section{Impact of food loss and waste on food availability/sustainability}

Nowadays, it is thought that one-third of the world's overall food produced by weight is lost or wasted ${ }^{16,17}$; however, the accuracy and usefulness of these broad statements is questionable. This is not to say that food waste is not a significant problem and that raising the issue is not 
important. Quite the contrary. The extent, accuracy, and resolution of available data on postharvest loss and waste is generally problematic since often methodologies are either not forthcoming, not sufficient robust or not clearly set out. As a result, the overall message is focussed too much on the extent of overall food waste rather than what should be done about it according to geographic and temporal resolution and need.

Definitions of food loss and waste are not universal. In general, food loss encompasses the reduction in the edible food dry mass or nutritional value across the supply chain (growing, harvest, processing, production, storage, transport, and distribution). Food waste is part of food loss; it commonly occurs in developed economies at both the retailer and consumer end, as a result of either poor planning or business decisions, as well as lack of technological infrastructure, capabilities or consumer awareness. ${ }^{18}$ Postharvest losses partly depend on the available technology in any one country and henceforth, on its agricultural and industrial development. Parfitt et al. ${ }^{19}$ consider these losses along a technological/economic gradient: 'developing', 'intermediate', and 'industrialised' food supply chains. The main causes of food loss and waste in developing countries originate from either cultural influences and/or financial, managerial, and technical resource constraints on harvesting techniques, cooling technologies, and storage facilities. ${ }^{18}$ Fruit and vegetables are the category with the highest amount of losses and waste followed by meat, fish and seafood, and milk; and within the fruit and vegetables the highest losses occur in the processing and packaging stage. ${ }^{20,21}$ Where a nation's development moves into a transitional phase, food loss is seen further along the food supply chain (storage and retailer rather than just production and transportation). In developed countries, the highest contribution to food waste often occurs at household level (e.g. $71 \%$ in the UK). ${ }^{12}$ At every step of the supply chain, food waste has an impact on economic (direct loss for farmers, retailers, and consumers), social (failure to secure food for a wider population) and environmental aspects (soil, water, energy implications and GHGe: greenhouse gas emissions). Terry et al. ${ }^{21}$ reported that the fruit and vegetable sector accounts for about $2.5 \%$ 
of the UK's overall GHGe. Potato has one of the highest level of GHGe, mostly because of the energy needed for cooking in the domestic stage. Garnett ${ }^{22}$ highlighted waste as the major area contributing to GHGe's within the UK fruit and vegetable sector, with most of the waste occurring at household and food service levels. It was reported that air freight and refrigeration are hotspots in the lifecycle of fresh produce, where the former accounts for approximately half of all GHGe's associated with transport. Other factors that contribute to waste, mostly in developed countries, are: i) how 'quality standard specifications' are set (aesthetic vs. nutritional or safe); ${ }^{11,22}$ for example, UK customers (retailers) tend to set their own quality standards for suppliers, which can be over and above the regulatory standards; ${ }^{23}$ ii) consumer's lack of understanding/misconception of food labelling - e.g. sell-by, best before, consume by, and expiry date; ${ }^{24}$ moreover, results from structured interviews with UK retailers, wholesalers, suppliers and others, showed that consumers were also confused by the ubiquitous use of promotions ('promotion fatigue') ${ }^{23}$ which could eventually lead to food waste at household level when buying more than what was needed. These examples illustrate that food waste can be tackled from different angles both by implementation of technological and innovative measures, and by changing attitudes and behaviour. As food waste not only impacts on a single sector but on multiple segments of society and environment, several different indicators for the level of food waste should be considered. From an economic point of view, one can monitor the waste at every step in the supply chain: rate of soil loss vs. regeneration; percentage of production resources waste; energy input per unit of production; quantity of harvest lost due to pests or diseases. Wasting food is primarily a social concern, given that 800 million live under extreme poverty ${ }^{25}$ and hunger.

\section{The way forward to reducing food loss and waste}

Despite the recognised negative impact of food waste on the environment, economy, and wider society, the worldwide evolution of food waste has steadily increased from 2004 to 2013 (Fig. 
1). That said, the difficulty and complexity of collating exhaustive food loss and waste data must be noted; greater data transparency is required both throughout the supply chain and among countries. In this context, clear accountability would be a prerequisite for managing and reducing waste. ${ }^{23}$ Data presented herein (Fig. 1) was taken from the FAOSTAT database and is focused on grain, fruit, and vegetable losses, which are most affected by postharvest processes and storage conditions. The total amount of food loss in 2013 was ca. 430 mega tonnes. ${ }^{16}$ It is not only that the absolute total amount of food waste has increased as a result of a growing world population over the last decade but, what is more remarkable, the contribution per capita to food waste (e.g. 47.2 and $62.4 \mathrm{~kg}$ capita $^{-1}$ in 2004 and 2013, respectively). ${ }^{16}$

Research and technological innovation should be the drivers for reducing food loss and waste by establishing true translation between industrialised and developing countries. Yet substantially more targeted and appropriate research should be carried out and implemented directly in low and middle-income countries; taking into account their particular circumstances and potential limitations (e.g. economic frameworks, infrastructures, energy supply and resilience, cultural and societal practices and behaviours etc.). Appropriate postharvest innovation is not just reliant on available postharvest human capital (Fig. 2) but on available funding mechanisms. Europe is one of the dominant areas for postharvest research, and has a relatively low input to global food loss $(c a .7 .7 \%) .{ }^{16}$ Whilst in Africa, which contributes approximately $18 \%$ of global postharvest food losses, the research base is too low across the continent, with the majority of research stemming from South Africa. There is a lack of mechanisms such as knowledge transfer programmes, internationally funded joint research and mobility schemes across supply chains, by which both conventional and innovative technologies can be developed and further implemented across the globe to reduce waste. Where collaboration does exist it is usually carried out on a bilateral basis which tends to ignore the geographic and temporal complexity and interconnectivity of global supply chains 


\section{Conclusions}

Food loss and waste is a complex problem that occurs in all stages of the supply chain, with many stakeholders involved. It ranges from postharvest losses to shortages in storage technologies and facilities, as well as demand forecasting and inventory planning issues. Behavioural attitudes of consumers have the greatest impact on the highest value-added food waste. There is a lack of skilled human capital and the existing networks of researchers focusing on food loss and waste are not fully connected. To tackle this global problem a multidisciplinary and collaborative research paradigm shift is required bringing together engineering and behavioural economics research that provides robust data regarding horticultural produce losses. Future efforts could be encouraged through providing funding schemes for recruiting highly qualified scientists and network building incentivising new frameworks to facilitate interdisciplinary collaborations.

\section{Acknowledgements}

The authors would like to thank Dr Daniel M. Simms for his technical contribution on the world maps plotting, and Professor Jerry Knox for his valuable commentaries on the manuscript.

\section{References}

1. United Nations, Department of Economic and Social Affairs, Population Division, World population prospects: The 2012 revision, highlights and advance tables. Working Paper No. ESA/P/WP.228, New York (2013).

2. Buzby JC and Hyman J, Total and per capita value of food loss in the United States. Food Policy 37(5): 561-570 (2012).

3. UNICEF, Food prices increases / Nutrition security: Action for Children. Food Prices Technical Note; July 4th, 2008. UNICEF Regional Office for East Asia and the Pacific, 
Bangkok (2008). http://www.unicef.org/eapro/Food_Prices_Technical_Note_july_4th.pdf.

4. Gross R, Schoeneberger H, Pfeifer H and Preuss J-HA, The four dimensions of food and nutrition security: definitions and concepts. SCN News 20, 20-25 (2000).

5. Capone R, El Bilali H, Debs P, Cardone G and Driouech N, Food System Sustainability and Food Security: Connecting the Dots. J Food Security 2 1: 13-22 (2014).

6. FAO, The state of the world's land and water resources for food and agriculture (SOLAW) - Managing systems at risk. Food and Agriculture Organization of the United Nations, Rome and Earthscan, London (2011).

7. World Economic Forum, Global Risks $2015,10^{\text {th }}$ Edition. World Economic Forum, Geneva, (2015).

8. Mekonnen MM and Hoekstra AY, Four billion people facing severe water scarcity. Science 2(2): e1500323 (2012).

9. Knox JW., Hess TM., Daccache A. and Wheeler T, Climate change impacts on crop productivity in Africa and South Asia. Environmental Research Letters 7034032.

10. Hall KD, Guo J, Dore M and Chow CC, The progressive increase of food waste in America and its environmental impact. PloS One 4(11): e790 (2009).

11. Aschemann-Witzel J, Waste not, want not, emit less. Science 352(6284): 408-409 (2016).

12. Food waste in England. House of Commons, Environment, Food and Rural Affairs Committee, London (2017).

13. Foley JA, Ramankutty N, Brauman KA, Cassidy ES, Gerber JS, Johnston M, Mueller ND, O’Connell C, Ray DK, West PC, Balzer C, Bennett EM, Carpenter SR, Hill J, Monfreda C, Polasky S, Rockström J, Sheehan J, Siebert S, Tilman D and Zaks DPM, Solutions for a cultivated planet. Nature 478: 337-342 (2011). 
14. Bjørndal T, Child A, Lem A and Dey MM, Value chain dynamics and the small-scale sector: A summary of findings and policy recommendations for fisheries and aquaculture trade. Aquac Econ Manag 19: 148-173 (2015).

15. Irani $\mathrm{Z}$ and Sharif AM, Sustainable food security futures. Perspectives on food waste and information across the food supply chain. Journal of Enterprise Information Management, 29(2): 171-178 (2015).

16. FAO (Food and Agriculture Organization of the United Nations), FAOSTAT Database. Rome, Italy. Retrieved May 2017 from http://www.fao.org/faostat/en/\#home. (2017).

17. FAO (Food and Agriculture Organization of the United Nations), The state of food and agriculture - Climate change, agriculture and food security. Food and Agriculture Organization of the United Nations, Rome (2016).

18. Gustavsson J, Cederberg C, Sonesson U, Van Otterdijk R and Meybeck A, Global food losses and food waste. Food and Agriculture Organization of the United Nations, Rome (2011).

19. Parfitt J, Barthel $\mathrm{M}$ and Macnaughton S, Food waste within food supply chains: quantification and potential for change to 2050. Phil Trans R Soc, 365: 3065-3081 (2010).

20. Nahman A and de Lange W, Costs of food waste along the value chain: Evidence from South Africa. Waste Management, 33: 2493-2500 (2013).

21. Terry LA, Mena C, Williams A, Jenney N and Whitehead P, Fruit and vegetables resource maps - RSC-008 (2011).

22. Garnett T, Fruit and vegetables \& UK greenhouse gas emissions: exploring the relationship. Food Climate Research Network working paper (2006).

23. Terry LA, Medina A, Foukaraki S and Whitehead P, Review of factors affecting fruit and vegetable demand - Defra report FO0438 (2013). 
24. Newsome R, Balestrini CG, Baum MD, Corby J, Fisher W, Goodburn K, Labuza TP, Prince G, Thesmar HS and Yiannas F, Applications and perceptions of date labeling of food. Compr Rev Food Sci Food Saf, 13: $745-769$ (2014).

25. World Bank Taking on Inequality. International Bank for Reconstruction and Development / The World Bank 1818 H Street NW, Washington, DC 20433 (2016). 


\section{Figures}

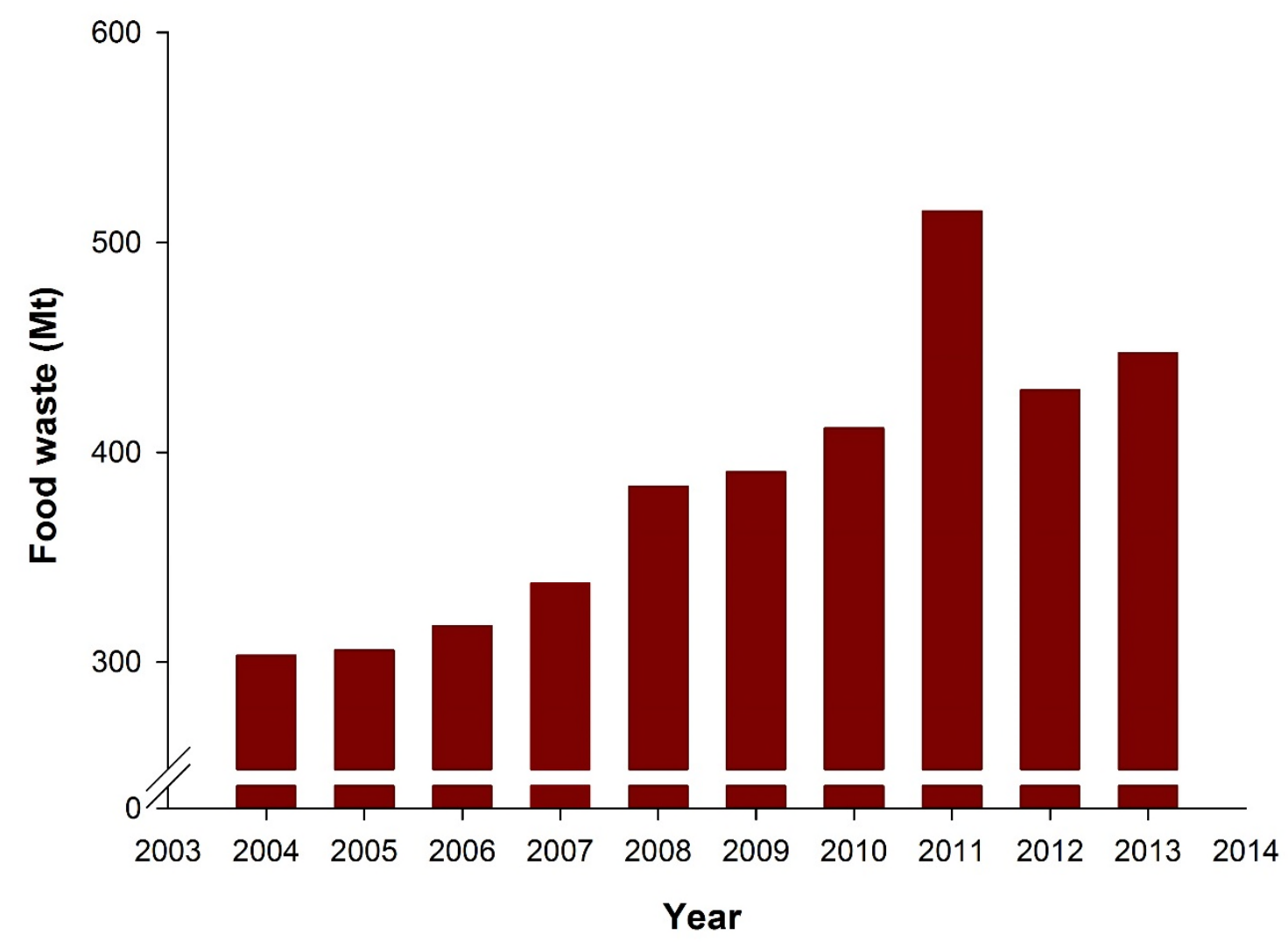

Figure 1. Food loss (grains, fruit, vegetables and derivate) evolution in weight (mega tonnes; Mt) per year from 2004 to 2013 according to FAOSTAT Statistics Database. ${ }^{16}$ 

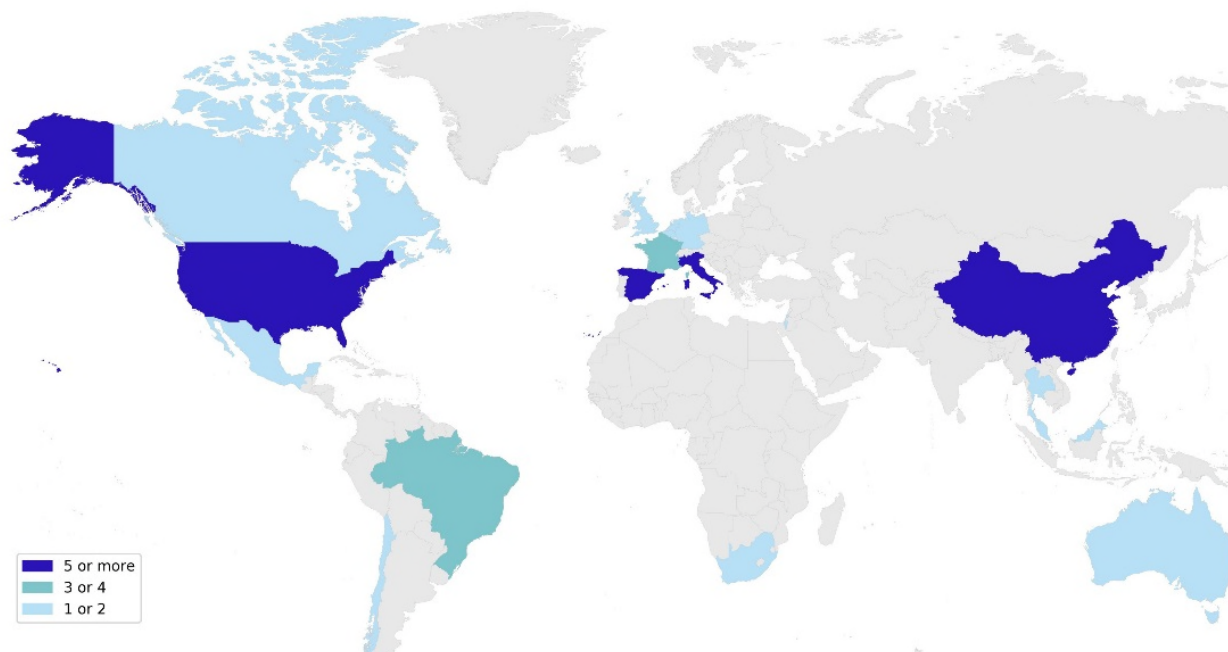

Figure 2. World map showing where the 50 most active postharvest institutions are located. Darker colour indicates higher number of research institutions for a specific country, whereas lighter colour indicates less number of institutions within a country. The institutions have been ranked by cross checking: i) Scopus statistics regarding first author's affiliation from peer reviewed publications; ii) Postharvest International Symposium presenters; and iii) Keynote speakers in international courses and conferences; over the last ten years. 